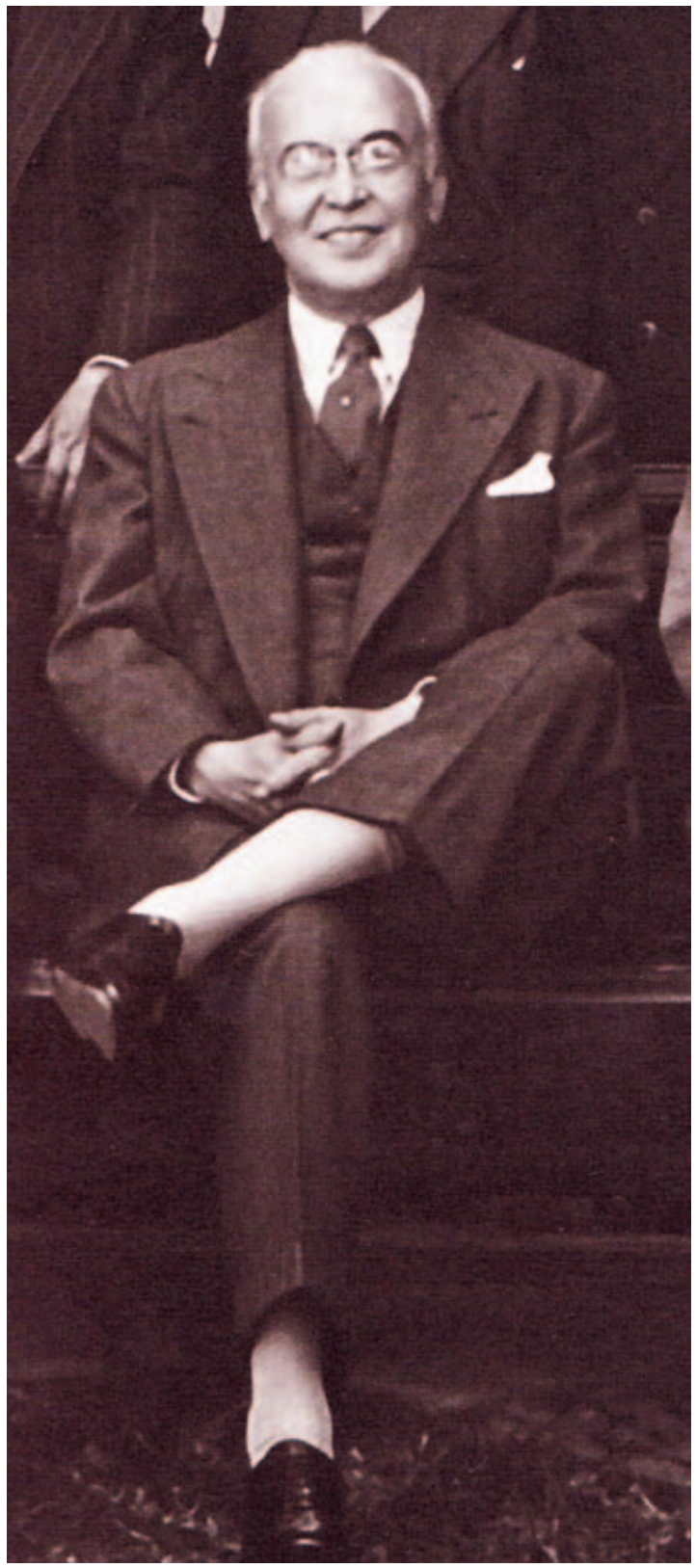

Julio Málaga Grenet, Sub-Director de la Escuela Nacional de Bellas Artes. Fuente: ENSABAP. Alma Máter de las Artes Plásticas Peruanas. Fondo Editorial ENSABAP. Lima, 2009. 


\section{Málaga Grenet en el recuerdo}

Raúl Rivera Escobar

Para nadie es un secreto que Arequipa haya dado algunos de los mejores cultores de la sátira gráfica en nuestro país. El característico sentir revolucionario e indomable de la gente del sur quizás sea uno de los argumentos más sólidos para entender el surgimiento de grandes caricaturistas entre los hijos de la blanca ciudad.

Sin embargo, por encima de todos aquellos maestros del lápiz y la ironía que con los años habrían de brillar en los fueros del periodismo nacional, sobresale indiscutiblemente la figura de un gran artista, cuya obra ha llegado a constituirse en el más emblemático referente visual, dentro del campo crítico-festivo, de la agitada realidad del siglo XX: Julio Málaga Grenet.

Nacido en 1886, Málaga supo desde joven apartar la caricatura de su carácter subalterno dentro de las artes. De oficio poco valorado la convirtió en medio para proyectarnos al mundo como nunca antes caricaturista peruano lo había hecho, dando cátedra a través de su extraordinaria producción, al estilo de los grandes creadores.

Fue Julio Alberto Castillo, director de Actualidades, quien un lejano día de 1904 rescatara a un jovencísimo Julio Málaga Grenet del cargado y rutinario ambiente burocrático de la Compañía Nacional de Recaudación, donde laboraba, para darle empleo estable como carica-
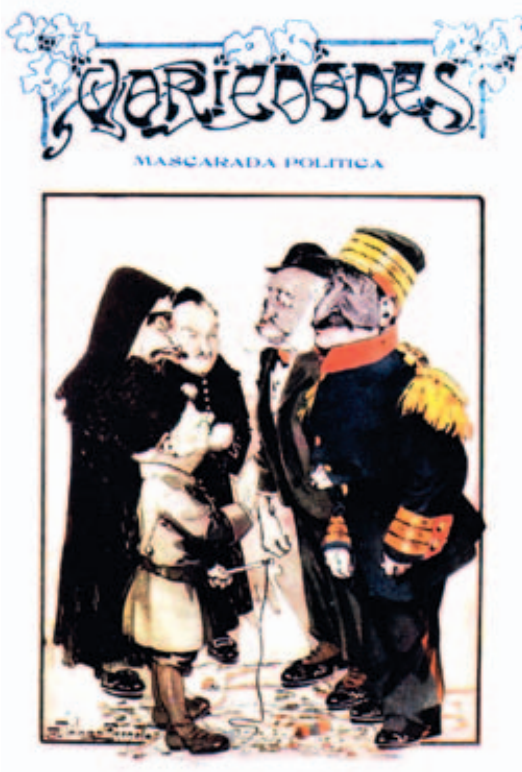

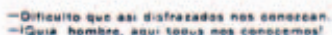

Primera carátula de "Variedades" (1908), por Málaga. turista en el conocido semanario.

De las siete Libras Peruanas que ganaba en aquella dependencia estatal, Málaga pasó a ganar diez, iniciando así una, tal vez inimaginada, carrera de éxitos en el medio artístico internacional. 

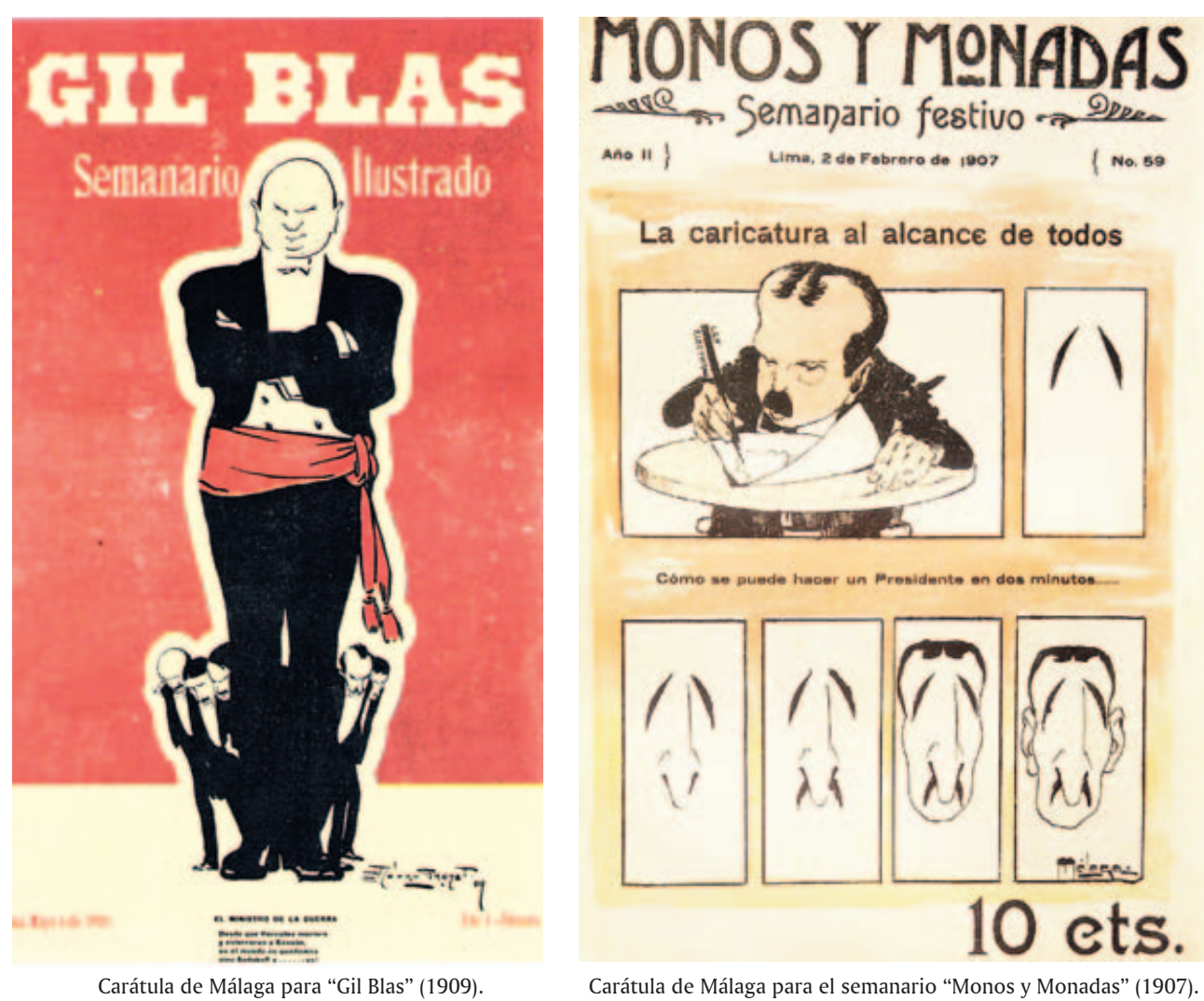

La caricatura al alcance de todos

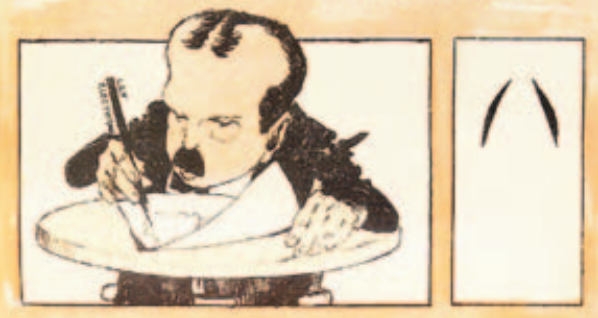

Como se puede hacer un Presidente en dos minutos.
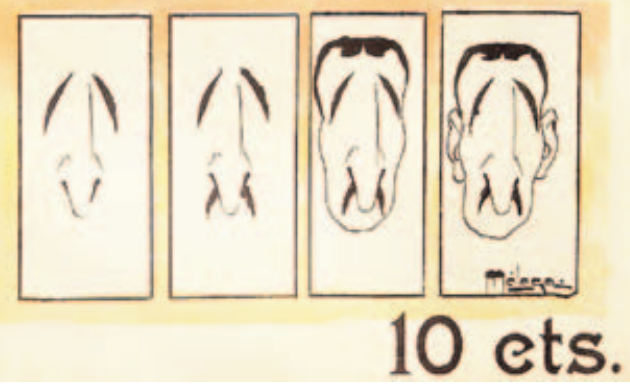

Carátula de Málaga para el semanario "Monos y Monadas” (1907).

Pronto, el ex-alumno de la vieja Academia Concha (donde llegara a conocer a, un ya anciano, Ricardo Palma) empezó a ganar rol protagónico en el ambiente periodístico local.

Apenas un año después de llegar a Actualidades, pasaría a incursionar en el manejo de medios periodísticos, al dirigir, con Leonidas Yerovi, Monos y Monadas. Un fino y mordaz humor, aunado a nuevas concepciones del arte caricaturesco, inspiradas en una mayor síntesis gráfica, llevaron a encumbrar a esta publicación como uno de aquellos íconos que resultan imprescindibles al hablar de la historia del periodismo nacional.

Desde 1908 colaboraría en la legendaria revista Variedades, experiencia a la que seguiría su fulgurante participación en medios como Ilustración Peruana, Gil Blas o El Fígaro.

Pero la actividad de Málaga no se limitaría sólo a obtener progresos en su oficio dentro de su patria. Recomendado por la esposa de Carlos Gildemeister, conoció en Chile a Agustín Edwards, dueño del diario El Mercurio, quien lo nombraría director artístico de su revista Zig Zag.

El prestigio de su lápiz no tardaría en ser reconocido también en Argentina, por entonces un importante centro de desarrollo de la caricatura, donde ocuparía la dirección artística de Caras y Caretas.

Fue allí donde alcanzó celebridad y fama considerables al liderar el movimiento que promovía el "nuevo procedimiento" en la caricatura iberoamericana, caracterizado por desterrar las deformaciones monstruosas, otorgando primacía a la síntesis de línea y forma, procurando registrar en rasgos esquemáticos el perfil psicológico del retratado. 
Como lo hiciera hasta el final de su carrera, el artista (quien solía silbar mientras dibujaba) no requería de bosquejos previos para sus dibujos, bastándole observar a sus modelos y estudiarlos, para luego reproducirlos de memoria, con breves trazos, en su casa.

Después de su exitoso paso por el periodismo argentino regresaría al Perú en 1916, colaborando con Excelsior y Don Lunes, otro memorable medio satírico donde ratificaría su renombre como dibujante y humorista.

En los años veinte, y tras desempeñarse como director artístico del suplemento dominical de La Nación, de Buenos Aires, encontramos a un Málaga consolidado y maduro, enfrentándose al competitivo ambiente artístico de Nueva York. También allí triunfaría, haciendo caricaturas, dibujos de modas, afiches, retratos o ilustraciones y publicando en títulos importantes como Cosmopolitan, Harpers o Good Housekeeping. En Norteamérica obtendría enorme éxito económico, logrando reunir cuantiosa fortuna, gran parte de la cual (invertida en acciones de la International Telephone \& Telegraph) perdería lastimosamente, durante la crisis de Wall Street en 1929.

No obstante, su genio iría con él a donde fuera. Así, en 1930, París, cuna de agudos y brillantes caricaturistas como Daumier, Toulouse-Lautrec o Forain, lo acogería generosamente, apareciendo sus dibujos en publicaciones afamadas como Le Matin.

Sólo en 1935 abandonaría su largo periplo por diversos países, iniciado décadas atrás, estableciéndose definitivamente en su patria. Dibujando para Cultura Peruana y Excelsior retomaría su carrera en el Perú, dedicándose luego a desarrollar la enseñanza del afiche (técnica en la que también alcanzara gran reputación) en la Escuela Nacional de Bellas Artes, institución cuya subdirección llegaría finalmente a ejercer desde 1945.

Un alumno de Bellas Artes, precisamente, llegaría a realizar un logrado busto en bronce de Málaga. Aquel retrato escultórico, conservado en casa del artista, le servía a éste para acomodar su sombrero y sus lentes cuando, ya mayor, regresaba de la calle.

Quizás en este gesto se pueda resumir la visión risueña de la vida de este ilustre peruano que, a través de una obra portentosa y única, supo con los años captar de manera ácida, pero imperecedera, el espíritu de toda una época.

Málaga fue el primer artista peruano de alcance universal. Conocido y respetado en su patria, Latinoamérica, Europa y los Estados Unidos, representa una de las claves para entender el inusitado despegue de la sátira y el humor gráfico a comienzos de la centuria anterior.

Hoy, a cincuenta años de su partida, su firma, convertida ya en leyenda, brilla aún en el privilegiado sitial al que sólo acceden los grandes maestros del arte universal. 